\title{
Thrombopenic purpura induced by a monoclonal antibody directed to a 35-kilodalton surface protein (p35) expressed on murine platelets and endothelial cells
}

\author{
Mercedes Rodríguez-Calvillo ${ }^{\mathrm{a}, *}$, Izaskun Gabari ${ }^{\mathrm{a}, *}$, Marina Duarte ${ }^{\mathrm{a}}$, \\ Guillermo Mazzolini ${ }^{\mathrm{a}}$, José Rifón ${ }^{\mathrm{b}}$, Eduardo Rocha ${ }^{\mathrm{b}}$, Jesús Prieto ${ }^{\mathrm{a}}$, and Ignacio Melero ${ }^{\mathrm{a}}$ \\ Departments of ${ }^{\mathrm{a}}$ Medicine and ${ }^{\mathrm{b}}$ Haematology, University of Navarra, Pamplona, Spain
}

(Received 2 October 2000; revised 4 December 2000; accepted 12 January 2001)

\begin{abstract}
Objective. With the aim of obtaining monoclonal antibodies (mAbs) against mouse endothelial surface antigens, immunization of rats with a mouse-derived endothelial cell line (PY4.1) and subsequent hybridoma production were performed.

Materials and Methods. One of the mAbs produced by hybridoma EOL5F5 was selected for its surface binding to endothelial cell lines, and identification of the mAb-recognized antigen was performed by immunoprecipitation. Experiments were performed to analyze the effects of EOL5F5 on systemic administration to mice.

Results. EOL5F5-recognized antigen was a single band of $35 \mathrm{kDa}$ under reducing and nonreducing conditions, features that do not match other known differentiation antigens with comparable tissue distribution. In vivo administration of purified EOL5F5 mAb to mice $(n=20)$ induced intense cutaneous purpura as well as severe but transient thrombocytopenia. Expression of EOL5F5-recognized antigen was detected on platelets from which it immunoprecipitated a moiety of identical electrophoretic pattern in SDS-PAGE, as the one recognized on endothelial cells. Immunohistochemically, EOL5F5-recognized antigen (p35) also was expressed on dermal capillaries, suggesting that, in addition to thrombocytopenia, damaging effects of the antibody on endothelial cells also might cause the observed purpura.

Conclusions. Our results show induction of thrombocytopenic purpura in mice with an mAb against a single antigenic determinant expressed on both platelets and endothelium. EOL5F5 mAb injection sets the stage for useful experimental models that resemble immune thrombocytopenic purpura. () 2001 International Society for Experimental Hematology. Published by Elsevier Science Inc.
\end{abstract}

\begin{abstract}
Introduction
Autoantibodies bind to platelet surface in several pathologic conditions, including immune thrombocytopenic purpura, systemic lupus erythematosus, and posttransfusion platelet immunization [1]. The common result of antibody binding, with or without complement fixation, is accelerated platelet destruction and thrombocytopenia [2,3]. The clinical presentation of the disorder varies widely, from the acute onset of petechiae and severe thrombocytopenia to the incidental

Reprint requests to: Ignacio Melero, M.D., Ph.D., Facultad de Medicina, Universidad de Navarra, C/Irunlarrea 1, 31008 Pamplona, Spain; E-mail: imelero@unav.es

*The first two authors contributed equally to this work.
\end{abstract}

laboratory discovery of asymptomatic thrombocytopenic patients. Sera from such patients usually contain immunoglobulin $\mathrm{G}$ (IgG) and/or immunoglobulin M (IgM) antibodies against platelet glycoprotein complexes, including GPIIb/IIIa [4,5], GPIb/IX [6,7], GPV [8], GPIa/IIa [5], GPIV [5], and other glycoproteins [9,10]. Antibodies in those sera frequently are pathogenic and cause complement fixation or opsonization, therefore targeting platelets for spleen and liver sequestration [2]. The reasons for antibody production in these autoimmune conditions are unknown, but in some cases are related to infection, drugs, concomitant neoplastic disease, or other conditions [11,12]. Prognosis usually is good, except when severe internal bleeding occurs. Treatment includes immunosuppressive drugs, sple- 
nectomy, intravenous immunoglobulin, and platelet transfusion among others [13].

It is well known that endothelial cells participate in inflammation, immunity, and coagulation, as do platelets, and they share the expression of many proteins expressed on the platelet surface [14-20]. These antigenic similarities are reflected in the common overlapping spectrum of autoimmune disorders, as sera from affected patients usually contain autoantibodies that react with different cell types [21]. We describe a protein identified on murine platelets and endothelial cell lines using a new monoclonal antibody (mAb) (EOL5F5). In vivo administration of this antibody causes severe thrombocytopenic purpura that spontaneously vanishes within 1 week. The antigen also is found on dermal endothelial cells, suggesting that dermal endothelial cell damage might contribute to the purpura. EOL5F5 mAb did not induce or inhibit platelet aggregation, but it seems to cause their destruction in vivo. Thus, the syndrome induced by systemically administered EOL5F5 antibody resembles immune thrombocytopenic purpura and establishes a useful experimental model to study this condition.

\section{Materials and methods}

Mice

$\mathrm{BALB} / \mathrm{c}^{\mathrm{nu} / \mathrm{nu}}$ mice were obtained from Harlan (Barcelona, Spain), housed in specific pathogen-free conditions, and used when they were between 6 and 18 weeks old.

\section{Cells and hybridoma production}

Wistar rats (Harlan) were immunized twice at 4-week intervals by intraperitoneal injection of $1 \times 10^{7}$ cells of the endothelial cell line PY4.1, derived from subcutaneous microvessels of SV40T transgenic mice (a generous gift from V. Bautch, Chapel Hill, NC, USA) [22], followed by two immunizations given intravenously at 6-week intervals $\left(1 \times 10^{7}\right.$ cells $)$ and a similar intravenous boost 3 days before hybridoma production. For hybridoma production [23], spleen cells from an immunized rat were fused with NSO myeloma cells (kindly provided by Dr. Milstein, Cambridge, United Kingdom) at a ratio of 5:1 and distributed in 96-well plates (Costar, Cambridge, MA, USA). Screening of mAb reaction with endothelial cell-surface antigens was performed by indirect immunofluorescence and flow cytometry (FACScan; Becton-Dickinson, San Jose, CA, USA). The mAbs were purified by affinity chromatography in sepharose protein-G columns (Pharmacia Biotech, Uppsala, Sweden), according to manufacturer's instructions.

\section{Platelet quantification and preparation of PRP}

For platelet quantification, 300- $\mu \mathrm{L}$ blood samples were obtained from $\mathrm{BALB} / \mathrm{c}^{\mathrm{nu} / \mathrm{nu}}$ mice by puncturing the retro-orbitary plexus with a citrated pipette. Automated quantification was performed using the Technicon-H1 (Bayer, Tarrytown, NY, USA), and manual counts were performed in a Neubauer chamber using a phase contrast microscope (Nikon).

For preparation of plasma rich in platelets (PRP), $1 \mathrm{~mL}$ of blood was drawn by direct heart injection using a citrated syringe. Blood was centrifuged at $110 \mathrm{~g}$ for 10 minutes, and the supernatant (PRP) was collected. For immunofluorescence, platelets were washed twice in phosphate-buffered saline (PBS) and $10 \mathrm{mM}$ EDTA (Gibco Life Technologies, Grand Island, NY, USA) and then immunostained.

\section{Immunofluorescence and flow cytometry}

For immunostaining, $2.5 \times 10^{5}$ of either platelets or endothelial PY4.1 cells were incubated for 30 minutes at $4^{\circ} \mathrm{C}$ with either EOL5F5, anti-CD31 (PharMingen, San Diego, CA, USA), or antiCD51 (PharMingen) $10 \mu \mathrm{g} / \mathrm{ml}$ in PBS (Gibco). Cells were washed twice and incubated for another 30 minutes at $4{ }^{\circ} \mathrm{C}$ with fluorescein isothiocyanate (FITC)-conjugated goat anti-rat IgG (Southern Biotechnology, Birmingham, AL, USA) and rewashed twice with PBS. For negative control, irrelevant rat IgG antibodies were used. Stained cells were analyzed using a FACScan flow cytometer (Becton-Dickinson). To assess the isotype of EOL5F5, indirect immunofluorescence was performed with FITC-tagged isotypespecific mAb (PharMingen).

\section{Surface biotin labeling and immunoprecipitation}

Either platelets or PY4.1 cells $\left(10^{7}\right)$ were washed three times in PBS (Gibco) and resuspended in PBS containing $0.4 \mathrm{mg} / \mathrm{mL}$ of sulfo-NHS-Biotin (Pierce, Rockford, IL, USA). After washing twice in cold PBS, cells were lysed in $1 \mathrm{~mL}$ of lysis buffer containing $1 \%$ Triton X-100 and $1 \mathrm{mM}$ PMSF. Equivalent amounts of lysates were used to immunoprecipitate with the mAb, as previously described [23]. Immunoprecipitates were analyzed by 10\% SDSPAGE and transferred onto a PVDF membrane (Immobilon-P; Millipore, Bedford, MA, USA). After saturation in warm PBS supplemented with $1 \%$ nonfat dry milk, blots were incubated with streptavidin-peroxidase (Streptavidin-HPR; Pierce) and developed by chemoluminescence using commercial reagents according to the manufacturer's instructions (ECL, Amersham-Pharmacia Biotech, Buckinghamshire, United Kingdom).

\section{In vivo experiments}

On day $0, B A L B / c^{n u / n u}$ mice $(n=8)$ were injected intraperitoneally with $300 \mu \mathrm{g}$ of purified EOL5F5. On days 1, 2 and 5, blood was drawn from the retrorbitary plexus using a citrated pipette and blood counts were performed. As a control, a group of BALB/ $/ \mathrm{c}^{\mathrm{nu} / \mathrm{nu}}$ mice was injected with $300 \mu \mathrm{g}$ of purified rat $\mathrm{IgG}$.

For bone marrow examination, once the mouse was sacrificed, bone marrow was flushed out from the hind limb bones and a small amount of marrow tissue was spread onto a glass slide. Bone marrow samples were stained with May-Grünwald-Giemsa and observed with a light microscope (Nikon).

\section{Platelet aggregation}

Platelet aggregation was carried out in citrated PRP (as described earlier) using a turbidimetric method in an aggregometer (Aggrecoder PA 3220; Menarini Diagnostics, Barcelona, Spain). PRP 300 $\mu l$ was placed in each cuvette in the aggregometer and incubated for 2 minutes with EOL5F5 or with control mAb (50 $\mu \mathrm{g}$ each). The aggregation was induced by adding $5 \mu \mathrm{M}$ ADP, $2 \mu \mathrm{g} / \mathrm{mL}$ of collagen, and $2 \mathrm{mM}$ of arachidonic acid (Menarini). In other experiments, EOL5F5 was tested to inhibit the aggregation induced by agonist agents by preincubating the platelets with $50 \mu \mathrm{g}$ of EOL5F5 mAb for 2 minutes, with subsequent addition of aggregation stimuli.

\section{Immunohistochemistry}

For immunohistochemical staining, skin from BALB/c $\mathrm{c}^{\text {nu/nu }}$ mice was embedded in Tissue-Tek OCT compound (Sakura, Zoeterwoude, 

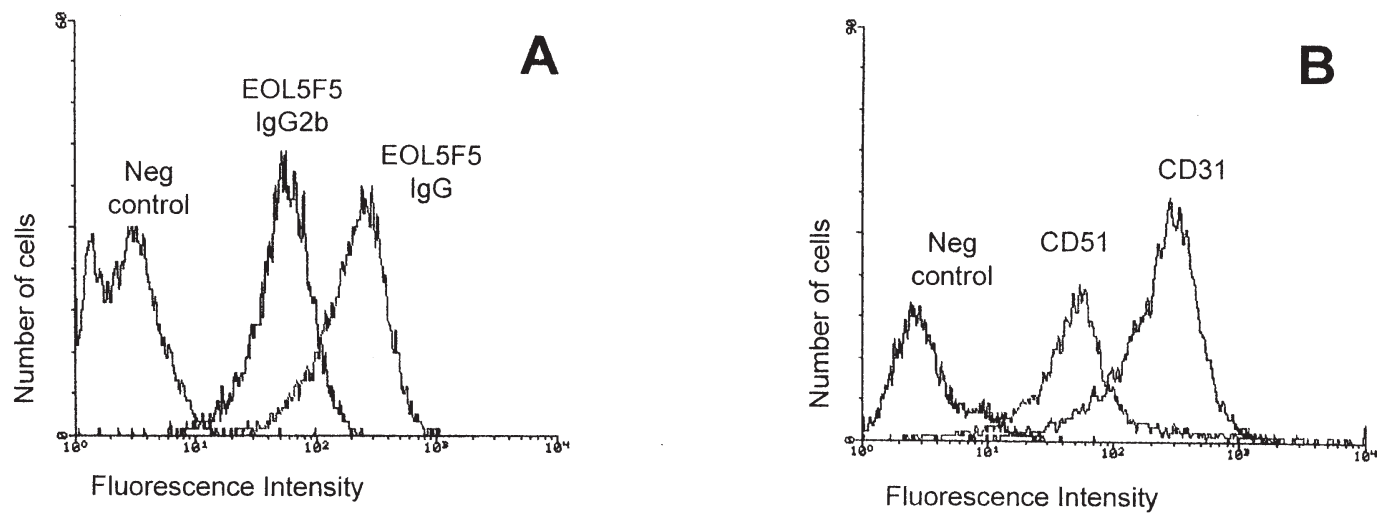

Figure 1. Obtainment of an anti-murine endothelium monoclonal antibody. (A) MAb EOL5F5 binding to the murine endothelial cell line PY4.1, which was used to immunize rats for $\mathrm{mAb}$ production, detected by indirect immunofluorescence developed with FITC-tagged antibodies either against whole rat IgG or with specificity to rat $\operatorname{IgG}_{2 b} \mathrm{mAb}$. (B) Indirect immunofluorescence analyzed by FACS of the expression of CD31 (PECAM-1) and CD51 ( $\alpha_{\mathrm{v}}$ ) on PY4.1.

The Netherlands), snap frozen in liquid nitrogen, and stored at $-80^{\circ} \mathrm{C}$. Tissue was sectioned on a cryostat at $6 \mu \mathrm{m}$, warmed at room temperature, air dried, and fixed in prechilled acetone for 10 minutes. After rinsing in PBS, endogenous peroxidase activity was neutralized using Dako peroxidase blocking reagent (Dako, Carpinteria, CA, USA). Sections were incubated with a rat mAb against mouse CD31 (Pharmingen) or with EOL5F5 mAb for 1 hour at room temperature. Anti-rat IgG peroxidase conjugate (Sigma) was used as secondary $\mathrm{Ab}$, according to manufacturer's instructions. The chromogenic substrate diaminobenzidine (Dako) followed by Mayer's hematoxylin counterstaining was used to visualize positive reactions.

\section{Results}

Obtainment and characterization of EOL5F5 antibody A panel of mAbs was obtained after immunization with a mouse-derived endothelial cell line (PY4.1) [22] by fusing splenocytes from immunized rats with mouse myeloma cells, as previously described [23]. The hybridoma EOL5F5 (rat IgG2b) (Fig. 1A) was selected for its surface binding to the endothelial cell line PY4.1 as detected by immunofluorescence and flow cytometry. It was shown that the PY4.1 endothelioma cell line intensely expressed well-known platelet-endothelial cell antigens, such as CD31 (PECAM) or CD51 $\left(\alpha_{v}\right)$ (Fig. 1B).

Biochemical characterization of the EOL5F5-recognized antigen was performed by immunoprecipitation from lysates derived from biotin-labeled PY4.1 cells. A single band of $35 \mathrm{kDa}$ was observed under reducing and nonreducing conditions, indicating that the newly obtained antibody was directed toward a single chain protein (Fig. 2). The electrophoretic mobility pattern of the antigen recognized by EOL5F5 does not match other known differentiation antigens with comparable tissue distribution.

\section{EOL5F5 mAb induces thrombocytopenic purpura}

When nude mice $(\mathrm{n}=20)$ were injected with $300 \mu \mathrm{g}$ of purified EOL5F5, an intense skin pattern of widely distributed petechiae was observed as early as 15 hours after inoculation (Fig. 3A). The general well-being of injected mice was preserved, and no deaths occurred in mice thus treated. Necropsies performed in selected mice sacrificed 24 hours after treatment in some cases revealed, in addition to the subcutaneous effusions, some subpleural bleeding and intraalveolar hemorrhages (Fig. 3B-D). It is noteworthy that respiratory distress was never noted, and mice did never show signs of being critically ill. No splenomegaly was detected, and no pathologic findings were found on bone marrow examination. Importantly, no clear changes in the number and morphology of megakaryocytes in bone marrow smears were observed.

Blood counts performed at the time of purpura appearance revealed severe thrombocytopenia (median lowest platelet count $55 \times 10^{3} / \mu \mathrm{L}$; mean normal count $375 \times 10^{3} /$ $\mu \mathrm{L}$, of 10 mice treated) as determined by an automated analyzer and confirmed by thorough examination of peripheral

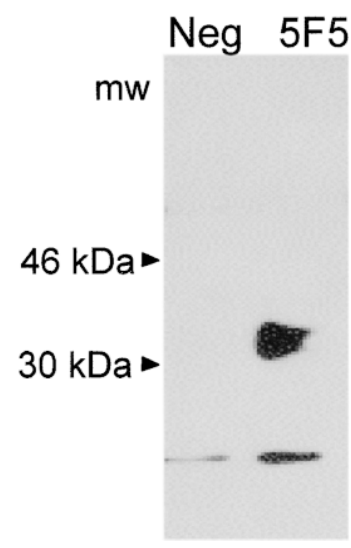

Figure 2. EOL5F5 immunoprecipitates a $35-\mathrm{kDa}$ surface protein from murine endothelial lines. SDS-PAGE analysis of the immunoprecipitates obtained with EOL5F5 mAb from lysates of biotin surface-labeled PY4.1 cells. As a negative control, protein-G sepharose beads without antibody were used. Data are representative of three experiments performed. 

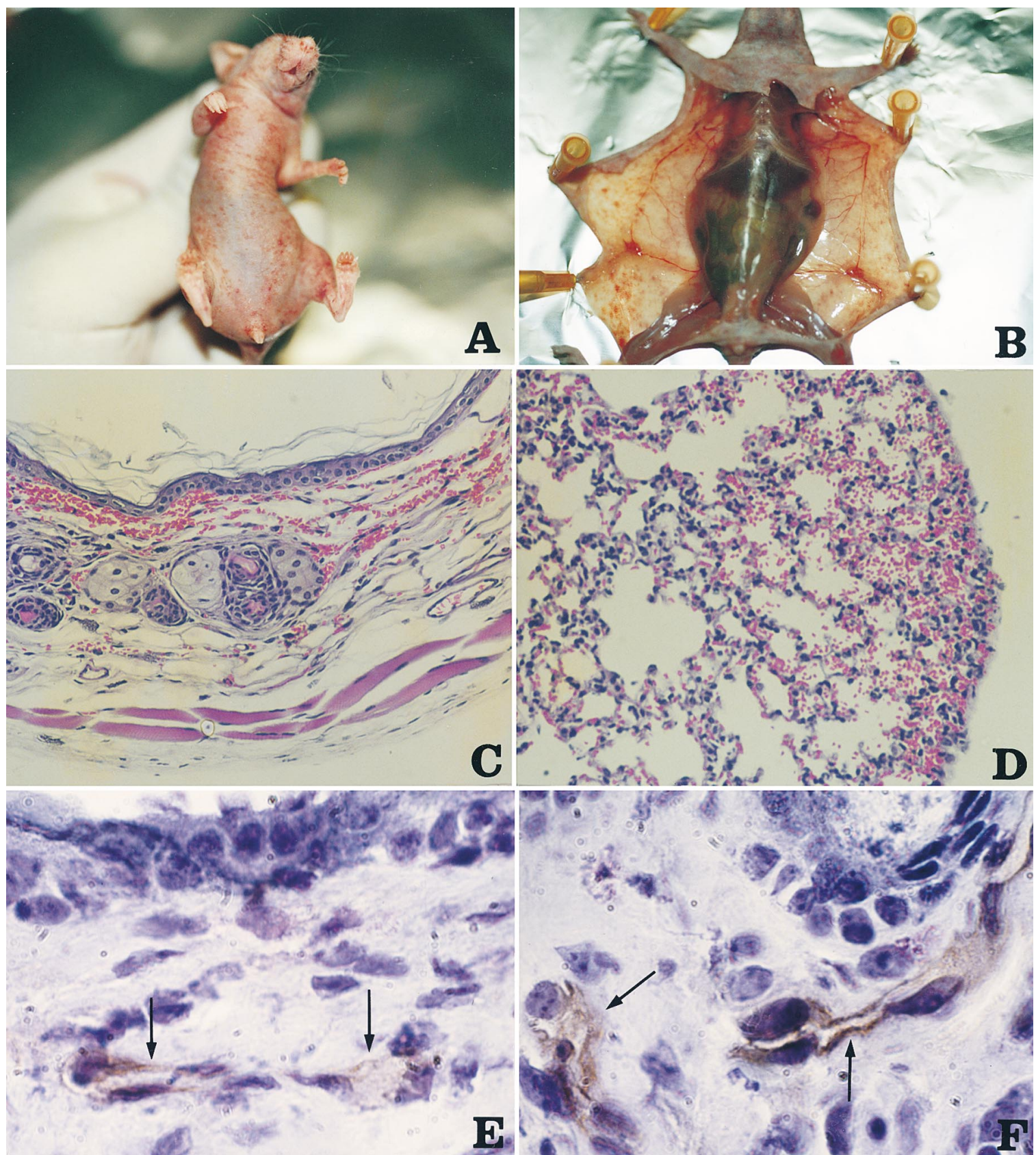

Figure 3. Intraperitoneal administration of EOL5F5 induces petechial purpura in mice. (A) BALB/ $\mathrm{c}^{\text {nu/nu }}$ mice injected intraperitoneally (300 $\left.\mu \mathrm{g} / \mathrm{mouse}\right) \mathrm{with}$ purified EOL5F5 developed multiple petechiae that was evenly distributed all over the skin. The photograph was taken 24 hours after mAb inoculation. Data are representative of more than 20 mice similarly treated. (B) Selected animals, as shown in (A), were sacrificed and subjected to thorough pathologic examination. Other than skin bleeding, no other gross signs of internal hemorrhage were noted. (C) Microphotograph of a skin section stained with hematoxylin and eosin showing subcutaneous hemorrhages. (D) Microphotograph of lung tissue showing signs of subpleural bleeding and intraalveolar extravasation of red cells. In some cases, point-shaped subpleural hemorrhages were noted macroscopically on careful inspection of the thoracic cavity (not shown). (E,F) Immunohistochemical staining of the skin of non-mAb-treated BALB/c nude mice with EOL5F5 (E) or anti-CD31 (F) showing the staining of endothelial cells forming capillaries (arrows).

smears. No variation was observed in the rest of the series (red cells and leukocytes) or in coagulation tests (activated partial thromboplastin time, prothrombin time, thrombin time, and fibrinogen quantification) performed to exclude a clotting dysfunction.
When platelet counts were sequentially followed in eight mice similarly treated (Fig. 4), complete disappearance of the petechiae was observed in about 3 days, in parallel to normalization of the peripheral blood platelet counts. Interestingly, 5 days after inoculation of the antibody, a counter- 


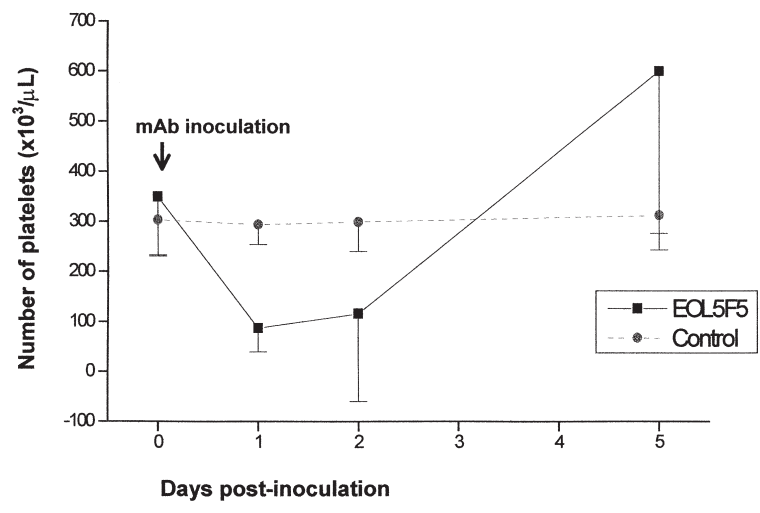

Figure 4. EOL5F5 mAb treatment induces transient thrombocytopenia. Sequential follow-up of platelet counts in BALB/c nude mice that received $300 \mu \mathrm{g}$ of purified EOL5F5 mAb $(\mathrm{n}=8)$ on day 0 (solid line) or rat $\mathrm{IgG}$ (dashed line).

acting rebound, over basal counts, in the number of platelets was detected in approximately half of the cases. This possibly reflects a compensatory mechanism, followed by a slow return to average counts. Remarkably, a second inoculation of antibody showed similar effects, at least in T-cell-deficient $\mathrm{BALB} / \mathrm{c}^{\mathrm{nu} / \mathrm{nu}}$ mice in which secondary antibody responses against rat $\mathrm{IgG}$ do not occur, indicating that treated mice do not become refractory to the effects of EOL5F5.

\section{EOL5F5 antigen expression on the platelet surface}

Observation of the in vivo effects caused by the mAb led us to study if the EOL5F5-recognized antigen also was expressed on the platelet surface. FACS analysis performed revealed that EOL5F5 bound to peripheral blood platelets of mice with higher intensity than did anti-CD31 mAb, as seen by indirect immunofluorescence staining (Fig. 5A). Human platelets were not recognized by EOL5F5 mAb under similar conditions, indicating that the epitope was not conserved among species (data not shown). Remarkably, an immunoprecipitation from biotin-labeled murine platelets also revealed a single band of $35 \mathrm{kDa}$, similar to that obtained from PY4.1 cells (Fig. 5B), indicating that platelets and endothelial cells share an identical molecule.

It is generally well known that in most patients with immune thrombocytopenic purpura, clearance of antibodycoated platelets by spleen macrophages is the main mechanism accounting for the thrombocytopenia [3]. However, in our case, thorough examination of the spleen did not reveal the presence of increased numbers of macrophages or changes in its structure such as those reported in immune thrombocytopenic purpura [24]. In order to assess the contribution of intravascular destruction to shortening of the platelet lifespan, we exposed washed platelets to murine whole serum as a source of autologous complement. After 2 hours of incubation, most platelets in the wells containing EOL5F5 and murine serum were disrupted, in contrast to platelets exposed only to either murine serum or to EOL5F5 $\mathrm{mAb}$ (data not shown). Thus, EOL5F5-induced thrombocytopenia could occur by intravascular destruction. It is of note that cell destruction was abolished if the sera were heat inactivated.

The possible effects of EOL5F5 mAb on mouse platelet activity were studied by setting aggregation assays. EOL5F5 added to platelets failed to induce aggregation, as would have been expected for a triggering receptor. In addition, EOL5F5 failed to change the intensity of the aggregation induced by ADP, collagen, or arachidonic acid (data not shown).

EOL5F5 antigen is expressed on dermal endothelial cells Immunohistochemical analysis of normal mouse skin showed that EOL5F5 mAb stained a number of vessels in

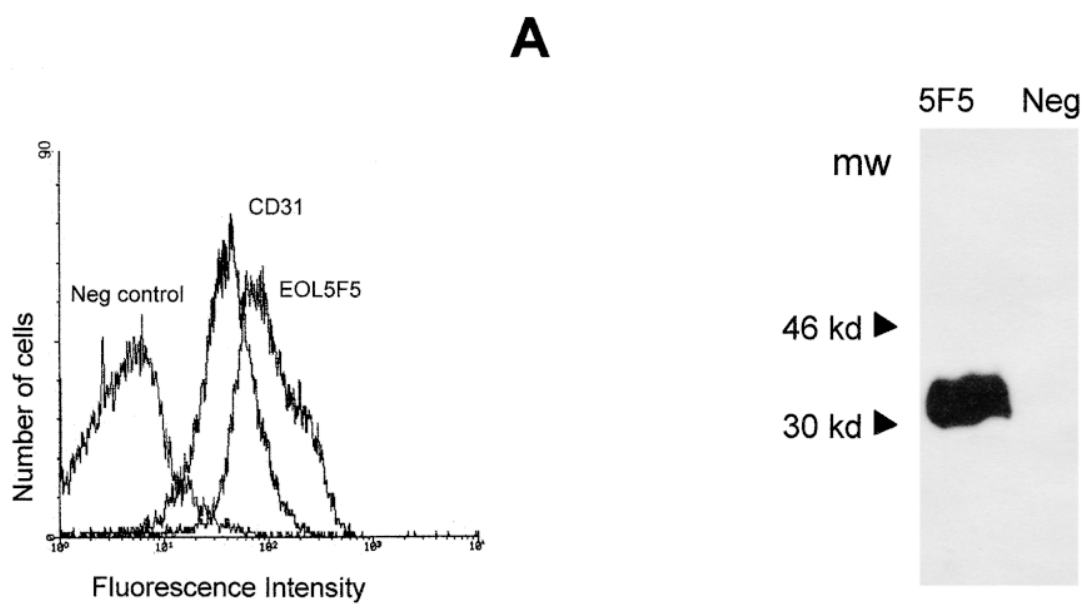

Figure 5. The antigen recognized by EOL5F5 is expressed on murine platelets. (A) FACS analysis of peripheral blood platelets on indirect immunofluorescence from BALB/c mice stained with EOL5F5 mAb, anti-CD31, or isotype-matched negative control. (B) SDS-PAGE analysis of immunoprecipitates obtained with EOL5F5 mAb from lysates of platelets surface labeled with biotin. As a negative control, protein-G sepharose beads without antibody were used. 
the dermis (roughly $30 \%$ compared to $\mathrm{CD} 31^{+}$vessels) (Fig. $3 \mathrm{E}$ and $\mathrm{F}$ ). Presence of the antigen in the skin is considered significant because of the selectivity of bleeding in this location when purpura developed (Fig. 3B and C). In addition to the dermis, EOL5F5 antigen is expressed at other vascular locations such as arterioles and some capillaries in skeletal muscle and pancreas, but hemorrhage was not noted in these organs.

\section{Discussion}

In this study, we defined a novel surface antigen expressed on murine platelets and endothelial cells with the help of a new mAb. In humans, surface differentiation antigens on platelets often are shared with endothelial cells, as is the case for the GPIIb-IIIa complex [15]; platelets GPIa-IIa and GPIc-IIa [16]; GPIb-IX and related protein on endothelial cells [17]; GMP140 [18]; CD9 [19]; and CD31 [20], among others. The common expression of surface antigens on endothelium and platelets is reflected in the clinical expression of several autoimmune disorders, which often include thrombopenia and vasculitis [25]. In vivo administration of EOL5F5 caused intense petechial purpura that resembles frequently occurring clinical conditions observed in patients. Causes of this type of purpuric syndrome usually are related to defects in primary hemostasia that involve thrombocytopenia, platelet dysfunction, or vascular damage [26]; however, we could not establish a clear involvement of the p35 antigen recognized by EOL5F5 mAb on platelet function. The lack of effect of the mAb on platelet aggregation could reflect that the protein is not involved in the process, but also that the epitope bound by the mAb is inert for the physiology of the molecule.

Pathogenesis of peripheral thrombocytopenia commonly involves the presence of circulating antibodies that bind blood platelets [27]. Our experimental model thus reflects the acute onset of an effector phase of antibody-mediated platelet destruction, because the mAb gains sudden access to platelets without need for the endogenous immune system to produce autoantibodies. We clearly detected severe thrombocytopenia in those animals treated, which is likely to be the main pathogenic factor. However, certain treated mice (approximately one third of total treated mice) developed a higher number of petechiae than would be expected from the intensity of the thrombocytopenia. Antibody-antigen reactions occurring on dermal endothelium, in accordance to our immunohistochemical data, also could play an important pathogenic role, as postulated in certain conditions. Recent data on sera from patients with drug-induced immune thrombocytopenia showed the presence of antiCD31 antibodies, an antigen shared by both platelets and endothelial cells. Therefore, endothelial damage is likely involved in their purpura [28].

Platelet dysfunction on a cell-to-cell basis was considered as a mechanism, but it seems unlikely because EOL5F5
mAbs did not hamper aggregation in vitro when platelets were preincubated with this $\mathrm{mAb}$.

Destruction of platelet precursors in bone marrow has not been studied in detail, but thrombocytopenia recovers swiftly and megakaryocytes are present in bone marrow smears, making these effects unlikely or clearly less important for the pathogenesis. Nevertheless, some studies revealed autoantibodies binding to either platelets intramedullary or megakaryocytes [29], thus affecting thrombopoiesis [30,31].

In our model, a rebound of platelet counts occurred after the thrombopenic phase in a number of cases. This probably reflects the effect of physiologic mechanisms monitoring platelet homeostasis. This model might be useful to study the underlying sensor mechanisms detecting thrombocytopenia and responding with biochemical stimuli, such as thrombopoietin, to promote thrombocytopoiesis [32] and therefore might be a useful tool in future research on these issues.

The molecular nature of the differentiation antigen recognized by EOL5F5 mAb (p35) awaits further characterization. In our laboratory, there is an ongoing study on cloning of its coding cDNA, whose sequence probably would be informative.

As a whole, our results show the induction of thrombocytopenic purpura in mice using an mAb against a single antigenic determinant expressed on both platelets and endothelium. EOL5F5 mAb injection establishes an interesting experimental model resembling frequently occurring clinical conditions in patients.

\section{Acknowledgments}

We thank Dr. V. Bautch for the generous gift of PY4.1 cells, Dr. Ortiz de Landázuri for human endothelial cells, and Drs. Santidrián, Ruiz, and Lucena for critical reading of the manuscript. Financial support was provided by CICYT (SAF99-0039). Dr. Rodríguez-Calvillo is a recipient of a fellowship from Fundación Española de Hematología y Hemoterapia.

\section{References}

1. Sinha AA, Lopez MT, McDevitt HO (1990) Autoimmune diseases. The failure of self-tolerance. Science 248:1380

2. Hauch TW, Rosse WF (1997) Platelet-bound complement (C3) in immune thrombocytopenia. Blood 50:1129

3. Kelton JG, Carter CJ, Rodger C, et al. (1984) The relationship among platelet-associated $\operatorname{IgG}$, platelet lifespan, and reticuloendothelial cell function. Blood 63:1434

4. Meyer M, Kirchmaier CM, Schirmer A, Spangenberg P, Strohl C, Breddin K (1991) Acquired disorder of platelet function associated with autoantibodies against membrane glycoprotein IIb-IIIa complex1. Glycoprotein analysis. Thromb Haemost 65:491

5. Beer JH, Rabaglio M, Berchtold P, et al. (1993) Autoantibodies against the platelet glycoproteins IIb/IIIa, Ia/IIa and IV and partial deficiency in GPIV in a patient with a bleeding disorder and a defective platelet collagen interaction. Blood 82:820

6. Devine DV, Currie MS, Rosse WF, Greenberg CS (1987) Pseudo-Ber- 
nard-Soulier syndrome: thrombocytopenia caused by autoantibody to platelet glycoprotein Ib. Blood 70:428

7. Kiefel V, Santoso S, Kauffmann E, Mueller-Eckhardt C (1991) Autoantibodies against platelet glycoprotein Ib/IX: a frequent finding in autoimmune thrombocytopenic purpura. Br J Haematol 79:256

8. Meenaghan M, Judson PA, Yousaf K, Lewis L, Pamphilon DH (1993) Antibodies to platelet glycoprotein $\mathrm{V}$ in polytransfused patients with hematological diseases. Vox Sang 64:167

9. Sugiyama T, Okuma M, Ushikibi F, Sensaki S, Kanaji K, Uchino H (1987) A novel platelet-aggregating factor found in a patient with defective collagen-induced platelet aggregation and autoimmune thrombocytopenia. Blood 69:1712

10. Deckmyn H, Van Houtte E, Vermylen J (1992) Disturbed platelet aggregation by collagen associated with an antibody against an $85-$ to $95-$ Kd platelet glycoprotein in a patient with prolonged bleeding time. Blood 79:1466

11. Doan CA, Bouroncle BA, Wiseman BK (1960) Idiopathic and secondary thrombocytopenic purpura: clinical study and evaluation of 381 cases over a period of 28 years. Ann Intern Med 53:861

12. Kaufman DW, Kelly JP, Johannes CB, et al. (1993) Acute thrombocytopenic purpura in relation to the use of drugs. Blood 82:2714

13. George JN, Woolf SH, Raskob GE, et al. (1996) Idiopathic thrombocytopenic purpura: a practice guideline developed by explicit methods for the American Society of Hematology. Blood 88:3

14. Montgomery RR, Kawai Y, Scott JP (1989) Homologous functions and interactions of platelets and endothelial cells. In: Kunicki TJ, George JN (eds.) Platelet immunobiology: molecular and clinical aspects. Philadelphia: JB Lippincott, p. 225

15. Phillips DR, Charo IF, Parise LV, Fitzgerald LA (1988) The platelet membrane glycoprotein IIb-IIIa complex. Blood 71:831

16. Pischel KD, Bluestein HG, Woods VL (1988) Platelet glycoproteins Ia, Ic, and IIa are physicochemically indistinguishable from very late activation antigens adhesion-related proteins of lymphocytes and other cell types. J Clin Invest 81:505

17. Sprandio JD, Shapiro SS, Thiagaraian P, McCord S (1988) Cultured human umbilical vein endothelial cells contain a membrane glycoprotein immunologically related to platelet glycoprotein Ib. Blood 71:234

18. McEver RP, Beckstead JH, Moore KL, Marshall-Carison L, Bainton DF (1989) GMP-140, a platelet $\alpha$-granule membrane protein is also synthesized by vascular endothelial cells and is localised in WeibelPalade bodies. J Clin Invest 84:92

19. Favaloro EJ, Moraits N, Koutts J, Exner T, Bradstock KF (1989) Endothelial cells and normal circulating hemopoietic cells share a number of surface antigens. Thromb Haemost 61:217

20. Newman PJ, Berndt MC, Gorski J, et al. (1990) PECAM-1 (CD31) cloning and relation to adhesion molecules of the immunoglobulin gene superfamily. Science 247:1219

21. Del Papa N, Gambini D, Meroni PL (1994) Anti-endothelial antibodies and autoimmune diseases. Clin Rev Allergy 12:275

22. Dubois NA, Kolpack LC, Wang R, Azizkhan RG, Bautch VL (1991) Isolation and characterization of an established endothelial cell line from transgenic mouse hemangiomas. Exp Cell Res 196:302

23. Melero I, Balboa MA, Alonso JL, et al. (1993) Signaling through the LFA-1 leucocyte integrin actively regulates intercellular adhesion and tumor necrosis factor-alpha production in natural killer cells. Eur J Immunol 231859

24. Sandler SG (2000) The spleen and splenectomy in immune (idiopathic) thrombocytopenic purpura. Semin Hematol 37:10

25. Meroni PL, Del Papa N, Raschi E, Tinacani A, Balestrieri G, Youinou P (1999) Antiendothelial cell antibodies (AECA): from a laboratory curiosity to another useful autoantibody. In: Schoenfeld Y (ed.) The decade of autoimmunity. Amsterdam, The Netherlands: Elsevier Science BV, p. 285

26. Bowie EJW, Owen AC (1991) Clinical and laboratory diagnosis of hemorrhagic disorders. In: Ratnoff OD, Forbes CD (eds.) Disorders of hemostasis, 2nd ed. Philadelphia: WB Saunders, p. 48

27. Bussel J, Cines D (1995) Immune thrombocytopenic purpura, neonatal alloimmune thrombocytopenia, and post-transfusion purpura. In: Hoffman R, Benz EJ, Shattil SJ, Furie B, Cohen HJ, Silberstein LE (eds.) Hematology: basic principles and practice. New York: Churchill Livingstone, p. 1849

28. Kroll H, Sun Q-H, Santoso S (2000) Platelet endothelial cell adhesion molecule-1 (PECAM-1) is a target glycoprotein in drug-induced thrombocytopenia. Blood 96:1409

29. McMillan R, Luicken GA, Levy R, Yelenovsky R, Longmire RL (1978) Antibody against megakaryocytes in idiopathic thrombocytopenic purpura. JAMA 239:2460

30. Heyns A du P, Badenhorst PN, Lotter MG, Pieters H, Wessels P, Kotze HF (1986) Platelet turnover and kinetics in immune thrombocytopenic purpura: results with autologous 111-In-labeled ad homologous 51-Cr-labeled platelets differ. Blood 67:86

31. Ballem PJ, Segal GM, Stratton JR, Gernsheimer T, Adamson JW, Slichter SJ (1987) Mechanisms of thrombocytopenia in chronic autoimmune thrombocytopenic purpura: evidence for both impaired platelet production and increased platelet clearance. J Clin Invest 80:33

32. Emmons RV, Reid DM, Cohen RL, et al. (1996) Human thrombopoietin levels are high when thrombocytopenia is due to megakaryocyte deficiency and low when due to increased platelet destruction. Blood $87: 4068$. 